\title{
EXPERIÊNCIAS DE EDUCAÇÃO EM AGROECOLOGIA EM ESCOLAS ITINERANTES E DE ASSENTAMENTO VINCULADAS AO MST NO PARANÁ: A FUNÇÃO SOCIAL DA ESCOLA NA CONSTRUÇÃO DA AGROECOLOGIA
}

\author{
EXPERIENCES OF EDUCATION IN AGROECOLOGY IN ITINERANT SCHOOLS AND \\ MST-RELATED SETTLEMENT IN PARANÁ: THE SOCIAL FUNCTION OF SCHOOL \\ IN THE CONSTRUCTION OF AGROECOLOGY
}

\author{
EXPERIENCIAS DE EDUCACIÓN EN AGROECOLOGÍA EN ESCUELAS \\ ITINERANTES Y DE ASENTAMIENTO VINCULADAS AL MST EN PARANÁ: \\ LA FUNCIÓN SOCIAL DE LA ESCUELA EN LA CONSTRUCCIÓN DE LA \\ AGROECOLOGÍA
}

Thaile Cristina Lopes Vieira*

\begin{abstract}
Resumo: A pesquisa teve como objetivos analisar experiências de educação em agroecologia, em escolas itinerantes e de assentamento vinculadas ao Movimento dos Trabalhadores Rurais Sem Terra - MST/Paraná e compreender qual a função social das escolas vinculadas a ele na construção da agroecologia. Para a realização deste trabalho de investigação, com abordagem qualitativa, utilizamos como procedimentos metodológicos a pesquisa bibliográfica, pesquisa documental e pesquisa de campo. Apresentamos elementos para entender como se materializa o movimento de incorporação da agroecologia no trabalho educativo da escola, por meio da análise de experiências desenvolvidas em seis escolas vinculadas ao MST no Paraná, que indicam alguns caminhos para a transformação da forma escolar capitalista e sintetizam o desafio assumido pelo MST, ao adotar a agroecologia como base para construção da Reforma Agrária Popular e para a formação da nova geração de camponeses. Uma das questões centrais explicitadas é a relação necessária entre educação e trabalho, que tem na agroecologia um potencial para se materializar e pode contribuir, mesmo que de forma parcial, para a emancipação humana.
\end{abstract}

Palavras-chave: Agroecologia. Movimento dos Trabalhadores Rurais Sem Terra (MST). Educação. Escola. Emancipação humana.

Abstract: The research aimed to analyze experiences of agroecology education in itinerant and settlement schools linked to the Landless Workers Movement - MST / Paraná, as well as to understand what is the social function of the schools linked to it in the construction of agroecology. This research is based on qualitative approach, which is used as methodological procedures the bibliographical research, the documental research and the field research. We present elements to understand how the movement of incorporation of agroecology in the educational work of the school materializes through the analysis of experiences developed in six schools linked to the MST in Paraná. They indicate some ways to the

\footnotetext{
* Mestre em Educação pela UNICENTRO. Especialista em Educação do Campo. Atua em áreas de supervisão pedagógica, agroecologia e ações com a juventude do campo, no CEAGRO - Centro de Desenvolvimento Sustentável e Capacitação em Agroecologia, em Laranjeiras do Sul/PR. E-mail: thaile.mst@gmail.com
} 
transformation of capitalist school form and synthesize the challenge assumed by the MST in adopting agroecology as the basis for the construction of Popular Agrarian Reform and for the formation of the new generation of peasants. One of the central issues is the necessary relationship between education and work, which has in agroecology a potential to be materialized and might contribute to human emancipation.

Keywords: Agroecology. Movement of Landless Rural Workers (MST). Education. School. Human emancipation.

Resumen: La pesquisa tuvo como objetivos analizar experiencias de educación en agroecología, en escuelas itinerantes y de asentamiento vinculadas al Movimiento de los Trabajadores Rurales Sin Tierra - MST/Paraná y comprender cuál a función social de las escuelas vinculadas a él en la construcción de la agroecología. Para la realización de este trabajo de investigación, con abordaje cualitativa, utilizamos como procedimientos metodológicos la pesquisa bibliográfica, pesquisa documental y pesquisa de campo. Presentamos elementos para entender cómo se materializa el movimiento de incorporación de la agroecología en el trabajo educativo de la escuela, por medio de la análisis de experiencias desarrolladas en seis escuelas vinculadas al MST en Paraná, que indican algunos caminos para la transformación de la forma escolar capitalista y sintetizan el desafío asumido por el MST, al adoptar la agroecología como base para construcción de la Reforma Agraria Popular y para la formación de la nueva generación de campesinos. Una de las cuestiones centrales explicitadas es la relación necesaria entre educación y trabajo, que tiene en la agroecología un potencial para materializarse y puede contribuir, mismo que de forma parcial, para la emancipación humana.

Palabras claves: Agroecología. Movimiento de los Trabajadores Rurales Sin Tierra (MST). Educación. Escuela. Emancipación humana.

\section{Introdução}

Esse artigo tem como objetivos analisar experiências de educação em agroecologia, em escolas itinerantes e de assentamento vinculadas ao MST/Paraná e compreender qual a função social das escolas vinculadas a ele na construção da agroecologia, por meio da análise de experiências desenvolvidas em seis escolas vinculadas ao MST no Paraná, no âmbito no projeto "Formação em Agroecologia dos Jovens do Ensino Médio das Escolas Itinerantes do Paraná: do saber popular ao conhecimento científico para o cuidado com a terra e com a vida".

Nessa perspectiva, antes de adentrar especificamente na apresentação e análise do desenvolvimento do projeto mencionado, compreendemos que é importante trazer alguns pressupostos e concepções do MST, que indicam caminhos para a transformação da escola e o lugar na agroecologia no seu projeto educativo. Tais elementos também sintetizam o esforço para inserir a agroecologia como um componente fundamental dos processos educativos nas escolas de acampamentos e assentamentos, o que integra o desafio assumido pelo MST, de adotar a agroecologia como base científica para construção da Reforma Agrária Popular e para a formação da nova geração de camponeses.

Com a preocupação de avançar na elaboração e na materialização desse desafio, o MST tem dedicado esforços e ações a partir da necessidade de discutir e aprofundar a sua formulação sobre como inserir e enraizar a agroecologia no currículo das escolas de educação básica. Os fundamentos que orientam essa construção no MST são o projeto da Reforma Agrária Popular, os aportes teórico-práticos da Agroecologia e a 
concepção de educação e de escola assumidos pelo Movimento. (MST, 2018a).

Nessa perspectiva, uma primeira questão a se considerar, ou reafirmar é a concepção de agroecologia do MST, que indica uma nova síntese entre o acúmulo histórico da agroecologia e os processos de lutas e formulações dos movimentos sociais camponeses vinculados à Via Campesina. Essa nova síntese se expressa na categoria agroecologia camponesa ou campesina, que é compreendida ao mesmo tempo como ciência, como prática social e como luta política. A novidade consiste na incorporação da dimensão da luta política à construção da agroecologia, na perspectiva de denúncia das contradições do agronegócio e de afirmação da agroecologia e da Reforma Agrária Popular como pilares do processo de reconstrução ecológica da agricultura. (MST, 2018b).

Uma segunda questão importante a ser delimitada é a concepção de educação e de escola assumidos pelo MST, entendendo que a construção do seu projeto pedagógico pela escola, iniciou-se no final da década de 1980, com o debate sobre o que queremos com as escolas de assentamentos e acampamentos. Porém, esse debate não iniciou pela escola em si, mas pelos objetivos formativos dos sujeitos para os quais o MST estava criando escolas nas áreas conquistadas. Os objetivos almejados desde então, de formar militantes continuadores da luta pela terra, pela reforma agrária e pela transformação social, capazes de lidar com os desafios da produção, de exercitar e construir novas relações sociais e econômicas, apontaram para além da escola. Porém, o MST tinha e tem o entendimento de que as escolas poderiam contribuir nessa formação, mas que a forma escolar capitalista não daria conta desses objetivos formativos, por isso, começou o debate e a construção da proposta de uma "nova escola”, que pudesse dar conta de sua tarefa específica como escola, o trabalho com o conhecimento, mas também de objetivos mais amplos. (CALDART, 2015).

\section{Concepção de educação do MST}

A forma do MST conceber a escola e o seu papel na formação fez com que produzisse uma teoria pedagógica - a Pedagogia do Movimento - que tem como matrizes formativas estruturantes da sua concepção de educação: a vida, e decorrente dela o trabalho, a cultura, a luta social, a organização coletiva e a história. No decorrer da trajetória de sua formulação pedagógica, o MST buscou inspiração e diálogo para pensar sua proposta de educação e escola na Pedagogia Socialista soviética e na Pedagogia do Oprimido e Educação Popular de Paulo Freire, experiências históricas da classe trabalhadora de diferentes lugares e épocas, comprometidas com a luta pela transformação social e que tentaram construir a nova escola, deixando como legado, além do acúmulo teórico, uma série de reflexões e aprendizados. Além disso, uma terceira fonte utilizada para essa construção foi o próprio Movimento, entendido como um grande educador coletivo, que pela sua dinâmica de funcionamento, estrutura organizativa e lutas é também uma experiência educativa. (MST, 2005; CALDART, 2015).

Dialogando com as suas referências teóricas, no decorrer de seus 34 anos de existência e luta, o MST elaborou também princípios pedagógicos e filosóficos que norteiam sua concepção de educação e de conhecimento, a saber: educação para a transformação social; educação para as várias dimensões do ser humano; educação com/para os valores humanistas e socialistas; educação como um processo permanente de formação e transformação humana; relação teoria e prática; a realidade e a pesquisa como base da produção do conhecimento e os tempos educativos; organização dos tempos educativos através de ciclos 
de formação humana; conteúdos formativos socialmente úteis; educação para o trabalho e pelo trabalho; educação para o trabalho e a cooperação; vínculo orgânico entre processos educativos e processos políticos, econômicos e culturais; gestão democrática; auto-organização dos educandos e formação permanente dos educadores. (MST, 2005).

Tais princípios, para além de fundamentar a prática educativa da escola, são norteadores da concepção de educação do MST, ancorada nos seguintes pressupostos: a educação entendida como processo de intencionalização da formação humana e uma concepção de conhecimento materialista histórica dialética, que tem o trabalho como atividade humana criadora e como princípio educativo na construção do ser humano como ser social e histórico. (MST, 2005, 2013).

Nessa perspectiva, não podemos confundir educação com escola, "se o que está em questão é a formação humana e se as práticas sociais são as que formam o ser humano, então, a escola, enquanto um dos lugares desta formação não pode estar desvinculada delas" (CALDART, 2004, p. 320), pois a formação humana acontece também fora da escola.
Os princípios pedagógicos e as concepções de educação e de conhecimento do MST indicam a centralidade e a necessidade do vínculo orgânico entre educação e trabalho. No entanto, para dar conta dos objetivos formativos a partir dessa dimensão central foi necessário incorporar novos elementos à proposta curricular: os Complexos de Estudo.

Nosso objetivo aqui não é aprofundar análises sobre a proposta em si, mas trazer alguns dos seus elementos estruturantes, considerando que o MST indicou que houve uma mudança de patamar no trabalho com a agroecologia nas escolas vinculadas ao MST no Paraná, a partir de 2013, com o processo de incorporação dos Complexos de Estudo.

A proposta dos Complexos articula três dimensões fundamentais na apreensão do conhecimento: o trabalho, a atualidade e a auto-organização. Os Complexos de Estudo se materializam por meio da unidade entre o trabalho material como método geral, as bases das ciências, das artes e da filosofia (conteúdos de ensino), processos de auto-organização dos estudantes, métodos específicos das disciplinas envolvidas, que utilizam as fontes educativas do meio onde o estudante vive e a escola está inserida. (MST, 2013).

Figura 1: Elementos da Proposta Curricular dos Complexos de Estudo.

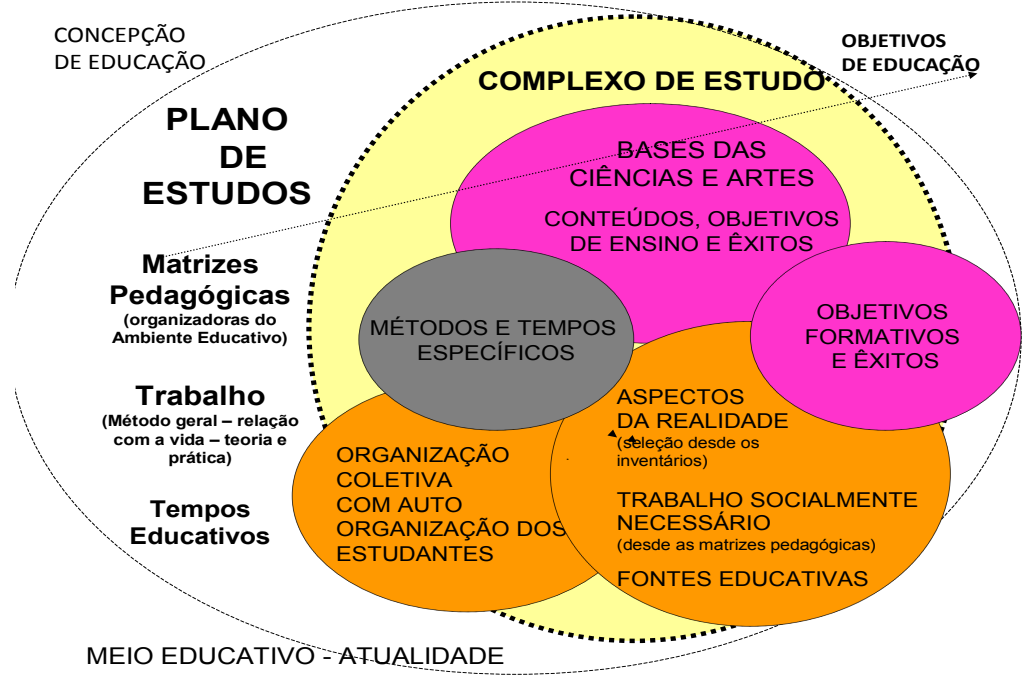

Fonte: MST, 2013. 
O trabalho, enquanto categoria e método de ensino nos Complexos de Estudo se constrói na necessidade material da existência humana em sua relação com a natureza e pela sua dimensão educativa, com intencionalidade pedagógica. Nessa perspectiva, o trabalho é pensado em uma dimensão social e necessária ao desenvolvimento das comunidades nas quais as escolas estão inseridas, na forma de trabalho socialmente necessário.

Enquanto atividade criadora do ser humano, que reorganiza a vida para sobreviver e se desenvolver, o trabalho garante o vínculo entre a vida e a capacidade de auto-organização. É o trabalho que garante a vinculação do desenvolvimento dos estudantes com a vida, com as contradições e com as lutas sociais.

O trabalho é o processo que estabelece a relação metabólica entre o ser humano e a natureza. Ao agir sobre a natureza externa e modificá-la por meio do trabalho, o ser humano modifica sua própria natureza. As relações capitalistas de produção provocaram uma falha metabólica irreparável, que coloca a exigência de uma restauração sistemática no metabolismo entre natureza e sociedade por meio do trabalho humano. (MARX, 2013).

O MST tem o trabalho como a categoria central de sua proposta pedagógica, fundamentada na articulação entre trabalho, auto-organização e ensino na organização do conteúdo e da forma escolar. Considera o trabalho como um dos pilares para romper com a forma hegemônica da escola capitalista e construir uma nova forma de escola, que seja coerente com as várias dimensões das matrizes formativas do ser humano. Reconhecemos aqui o potencial educativo do trabalho, como o fio condutor da educação como processo de intencionalização da formação humana, pois é por meio dele que o ser humano aprende e se desenvolve também e principalmente nas relações estabelecidas com o meio social no qual está inserido e é também por meio do trabalho que é possível construir novas relações sociais e de produção.

Nesse sentido, exercitar processos de auto-organização, enquanto um princípio pedagógico, por meio de formas de trabalho socialmente necessário à escola e ao seu entorno é uma tarefa que não diz respeito apenas à escola. É preciso planejar e desenvolver com os estudantes situações que podem e devem ser realizadas dentro e fora da escola, tendo em vista que o que o MST pretende construir com isso, os objetivos formativos que exigem espaços e processos em que os estudantes exercitem formas de trabalho e de auto-organização no próprio Movimento, e a escola pode ajudar nisso. (VIEIRA, 2016).

Ressaltamos que a principal diferença da proposta por Complexos em relação às demais propostas curriculares diz respeito à preocupação central com a formação humana omnilateral, pois tem como principal objetivo a formação de lutadores e construtores da Reforma Agrária Popular na luta para a transformação social. Para atender tal objetivo, o MST entende que é necessário transformar o conteúdo e a forma da escola. Considerando o contexto histórico que vivenciamos, do ponto de vista tático, o MST entende que é necessário manter e fortalecer a construção de iniciativas e movimentos contra-hegemônicos no contexto escolar, sem perder de vista seus objetivos estratégicos mais amplos.

Nessa perspectiva, a incorporação dos Complexos de Estudo potencializou as possibilidades de trabalho pedagógico com a agroecologia, evidenciando que a luta pela transformação da forma escolar está em sintonia com a luta pela transformação social e pela construção de um novo projeto de campo, no qual a agroecologia é um pilar fundamental.

A partir dos desafios formativos da atualidade da luta pela terra e pela Reforma 
Agrária Popular, considerando a correlação da luta de classes no campo e a disputa de projetos antagônicos de agricultura, o MST aponta para uma necessária relação entre educação e agroecologia, uma relação que possibilite aos estudantes das escolas do campo a apropriação da teoria e da prática da agricultura de base agroecológica. (CALDART, 2015; MST, 2017a).

Consideramos importante trazer esses elementos de concepções e fundamentos, que situam nosso objeto de pesquisa no contexto da luta do MST, que demonstram sua preocupação em construir uma proposta de "educação em agroecologia” para as escolas de educação básica que dialogue com seus objetivos formativos e que oriente o estudo e a prática da agroecologia nas escolas, numa perspectiva de totalidade.

A partir disso, apresentamos na sequência, o contexto e o relato das experiências de trabalho com agroecologia realizadas em seis escolas vinculadas ao MST no Paraná, para compreender como está se materializando no chão da escola a relação educação e agroecologia e em seguida apontar elementos de análise que permitam compreender qual a função social das escolas do campo vinculadas ao MST na construção da agroecologia. Salientamos que essa é uma das experiências realizadas, mas não a única.

\section{Projeto Formação em Agroecologia dos Jovens do Ensino Médio das Escolas Itinerantes do Paraná: do saber popular ao conhecimento científico para o cuidado com a terra e com a vida}

O Paraná possui nas áreas de reforma agrária doze escolas itinerantes, vinte e cinco colégios estaduais (anos finais do ensino fundamental e ensino médio), cento e vinte escolas municipais e três centros de formação em agroecologia. Porém, o MST tem maior incidência nas escolas itinerantes de acampamentos. Até o ano de 2012 a inserção da agroecologia nas escolas se dava principalmente por meio de projetos esporádicos e projetos complementares realizados em contra turno. Não havia ainda uma compreensão aprofundada dentro das escolas, sobre a importância do trabalho com a agroecologia como um componente fundamental e estratégico da proposta educativa do MST. (MST, 2017b).

As principais práticas realizadas eram as hortas, com poucos estudos realizados e de forma aleatória, detendo-se ao âmbito da prática e subsidiada por alguns projetos. A partir de 2013, de forma articulada à proposta dos Complexos de Estudo, a agroecologia passou a ocupar outro patamar nas escolas, aparecendo principalmente a partir das porções da realidade, ainda de forma aleatória, contudo, aprofundou-se a importância de trabalhar esse tema no Plano de Estudos1 das escolas e passou a ocupar um lugar central na formação continuada dos educadores e educadoras das escolas itinerantes e de algumas escolas de assentamento. (MST, 2017b).

De acordo com Leite \& Sapelli (2017), as preocupações com a produção agroecológica e o trabalho socialmente necessário demonstram um potencial educativo relacionado a um entendimento claro sobre a relação entre o trabalho socialmente necessário e a agroecologia, que tem feito parte da construção da proposta de educação do MST. Essas

\footnotetext{
${ }^{1}$ Por plano de estudos deve-se entender o conjunto de decisões que fornece aos educadores elementos para definir a amplitude e profundidade dos conteúdos a serem ensinados, os objetivos tanto de caráter formativo como de ensino, as expectativas de desenvolvimento, as indicações das relações que tais conteúdos e objetivos têm com a vida cotidiana dos estudantes, bem como orientações metodológicas gerais que conduzam a uma organização da escola e do ensino com significado para os estudantes do campo. (MST, 2013, p. 3).
} 
preocupações foram adentrando as escolas vinculadas ao Movimento, principalmente a partir do entendimento sobre a necessidade de um ensino que tenha como ponto de partida a realidade e a vida e que se vincule ao trabalho e à luta social, em relação aos conhecimentos historicamente produzidos pela sociedade.

A partir de 2013, o processo de implementação da proposta curricular dos Complexos de Estudo produziu uma série de mudanças significativas na organização do trabalho pedagógico de um conjunto de escolas vinculadas ao MST no Paraná, potencializando principalmente os processos de planejamento coletivo a partir da realidade do entorno das escolas, a auto-organização dos estudantes, a relação entre trabalho e conteúdo escolar e os processos de formação continuada de educadores. Como resultado desse processo, há um movimento que evidencia nas escolas, práticas ou ensaios de formas de trabalho socialmente necessário vinculadas à agroecologia, que articulam a dimensão do estudo, do trabalho social e da auto-organização dos estudantes. A construção do vínculo entre educação e agroecologia nas escolas remete a objetivos formativos que estão em sintonia com os fundamentos do programa de Reforma Agrária Popular do MST, para o enfrentamento ao modelo do agronegócio e construção de outro projeto de campo. A partir desse entendimento, o MST identificou que era necessário avançar na formação da consciência agroecológica, o que coloca a exigência de acesso a um conjunto de conhecimentos de diferentes ciências e a superação da separação entre o trabalho manual e o trabalho intelectual, que foram cindidos pelo capital com o processo da divisão social do trabalho. (LEITE; SAPELLI, 2017).

De acordo com os autores, essas preocupações, somadas ao potencial pedagógico e educativo das práticas introdutórias à agroecologia que estavam sendo desenvolvidas nas escolas, motivaram o MST a buscar uma parceria junto à Universidade Estadual do Centro Oeste do Paraná - Unicentro, para implementar um projeto de formação em agroecologia, o que possibilitou a aprovação do Projeto Formação em Agroecologia dos Jovens do Ensino Médio das Escolas Itinerantes do Paraná: do saber popular ao conhecimento científico para o cuidado com a terra e com a vida, sob a coordenação do LAEC - Unicentro.

O projeto envolveu 17 escolas de acampamentos e assentamentos vinculados ao MST no Paraná, porém a implementação de experiências em agroecologia aconteceu em seis escolas, a saber: Colégio Estadual do Campo $1^{\circ}$ de Setembro, localizado no Assentamento Egídio Brunetto, em Rio Branco do Ivaí; Escola Itinerante Caminhos do Saber, Acampamento Maila Sabrina, em Ortigueira; Escola Itinerante Herdeiros da Luta de Porecatu, Acampamento Herdeiros da Luta de Porecatu, em Porecatu; Escola itinerante Herdeiros do Saber, Acampamento Herdeiros da Terra de $1^{\circ}$ de Maio, em Rio Bonito do Iguaçu; Colégio Estadual do Campo Aprendendo com a Terra e com a Vida, Assentamento Valmir Motta de Oliveira, em Cascavel; Escola Itinerante Valmir Motta de Oliveira, Pré-Assentamento Companheiro Keno, em Jacarezinho. (SAPELLI, 2017a; LEITE; SAPELLI, 2017).

Uma característica importante é o perfil das escolas atendidas pelo projeto. Todas as escolas envolvidas no projeto são da rede estadual de ensino, tendo como mantenedor o governo do Paraná. Uma das características desse vínculo formal é a forma de contratação dos professores que atuam nos anos finais do Ensino Fundamental e no Ensino Médio, a inserção desses profissionais nas escolas se dá via regime do Processo Seletivo Simplificado - PSS, uma forma de contratação temporária (anual). A contratação dos 
professores dos anos iniciais e da coordenação da escola acontece por meio de um convênio entre o governo do Paraná e a Associação de Cooperação Agrícola e Reforma Agrária do Paraná - ACAP, uma entidade jurídica de direito privado vinculada ao MST.

De acordo com Leite e Sapelli (2017), esse convênio garante o amparo legal que dá sustentação à proposta pedagógica e é por meio dele que, desde 2003, o MST vivencia no Paraná a experiência de educação formal da Escola Itinerante nos acampamentos. E foi justamente a materialidade das Escolas Itinerantes e o avanço da teoria pedagógica que colocou para o MST a exigência de novos elementos para avançar na transformação do conteúdo e da forma escolar, o que resultou na construção da proposta dos Complexos de Estudo.

Compreendemos também que é importante mencionar que apesar de todas as escolas participantes do projeto serem vinculadas ao MST, tem um elemento diferencial entre elas, há um grupo composto por Escolas Itinerantes de acampamentos e outro grupo que são escolas de assentamentos. Esse diferencial carrega a especificidade da Escola Itinerante, por estar vinculada a processos e a conflitos de luta pela terra, na condição de ocupações que se organizam na forma de acampamento e, portanto, correm o risco de "despejos" (reintegração de posse judicial realizada na maioria das vezes pela polícia, que expulsa as famílias das áreas ocupadas). Então, essa escola é marcada pela condição da itinerância justamente porque deve acompanhar as famílias acampadas, para garantir o direito do acesso à educação e à escolarização. Devido a essa condição entende-se que o MST tem maior controle no processo de organização da escola e do acampamento, sendo a materialidade da Escola Itinerante um pouco diferente das escolas de assentamentos, em termos de hegemonia e controle do território sob direcionamento do Movimento.
De 2003 até 2017, segundo Sapelli (2017b, p. 47), "[...] foram criadas vinte e quatro escolas itinerantes, destas, sete passaram a funcionar em assentamentos/pré-assentamentos, cinco cessaram suas atividades e doze continuam como escolas de acampamento."

Ainda segundo a autora, entre 2010 e 2013 houve um decréscimo em relação ao número de escolas itinerantes, relacionado à diminuição do número de famílias acampadas no Paraná, porém, em 2017 o número de escolas passou a crescer novamente, passando a ser doze, especialmente devido à retomada de grandes ocupações de terra com a criação de novos acampamentos entre o período de 2014 e 2015.

Dentre os aspectos que merecem destaque, está o perfil das comunidades das quais as escolas que fizeram parte do projeto estão inseridas, acampamentos e assentamentos marcados pela pobreza, pela falta de políticas públicas e pela presença ambígua de pequenos agricultores Sem Terra, ligados tanto à produção de alimentos quanto à produção de commodities, porém sob a hegemonia do modelo do agronegócio, mesmo nos acampamentos. A presença da escola acaba sendo uma referência mobilizadora da própria comunidade, como espaços de reunião, de debate e motivação coletiva dos problemas que atingem a comunidade como um todo. Nessas comunidades, principalmente nos acampamentos, dado o vínculo mais efetivo com processo de luta e enfrentamento do MST, o debate político marcado pela disputa de modelos de agricultura (agronegócio X agricultura camponesa de base agroecológica) é presente, embora também nos assentamentos, mas em menor intensidade. Como as escolas tornam-se "centros" de referência das comunidades camponesas, o MST entende que podem e devem oportunizar este debate, desde a fase inicial da escolarização. 
Nessa perspectiva, em relação ao projeto Formação em Agroecologia dos Jovens do Ensino Médio das Escolas Itinerantes do Paraná: do saber popular ao conhecimento científico para o cuidado com a terra e com a vida, Leite e Sapelli (2017, p. 67) apontam que “[...] a realização de práticas agroecológicas suscitaria, nas comunidades, debates importantes e a explicitação de algumas contradições presentes na forma de produção, bem como representavam possibilidades de trabalho pedagógico.”

As principais atividades realizadas foram: a criação de seis Grupos de Estudo, Pesquisa e Experimentação Jovem - GEPEJOVEM nas escolas envolvidas, para realizar estudos no local; a realização de três encontros de formação ${ }^{2}$ continuada com educadores, estudantes e pessoas das comunidades (maio e setembro de 2016 e abril de 2017); realização de visitas técnicas dos estudantes a locais onde são implementadas experiências de agroecologia; ida de técnicos aos acampamentos para acompanhar o desenvolvimento e orientarem a realização de práticas agroecológicas; intervenção em campos experimentais de agroecologia nos acampamentos e assentamentos; além da sistematização das experiências e conhecimentos produzidos com o projeto na forma de caderno. (SAPELLI, 2017a; LEITE; SAPELLI, 2017).

\footnotetext{
${ }^{2}$ Nestes encontros, além dos momentos de estudo sobre diferentes dimensões da agroecologia, envolvendo desde práticas de produção agroecológicas, aspectos das relações humanas e de gênero até questões pedagógicas do currículo escolar, também ocorreram momentos de socialização e apresentação dos resultados das atividades realizadas nas escolas e comunidades, visitas técnicas, oficinas, trocas de experiências, momentos de elaboração de planejamentos para articular a agroecologia aos conteúdos escolares. Participaram destes encontros, além de estudantes, professores e pessoas das comunidades, docentes de várias universidades públicas, integrantes do MST e da Rede Ecovida de Agroecologia. (SAPELLI, 2017a; LEITE; SAPELLI, 2017).
}

\section{Práticas agroecológicas desenvolvidas nas escolas participantes do projeto}

As experiências de agroecologia desenvolvidas pela Escola Itinerante Caminhos do Saber, no Acampamento Maila Sabrina, em Ortigueira, Paraná no âmbito do projeto foram a construção de uma horta mandala, de uma agrofloresta e a recuperação e proteção de duas nascentes. Estas foram definidas a partir do mapeamento de necessidades e demandas da comunidade, em decorrência da materialidade da produção existente no acampamento, devido ao uso de práticas convencionais que levavam à destruição do solo, à contaminação das nascentes, o uso de agrotóxicos. Essa materialidade provocou inquietações didático-pedagógicas que suscitaram a escola a definir por aquelas práticas agroecológicas. (LEITE; SAPELLI, 2017).

A prática da recuperação e proteção de nascentes envolveu estudantes e pessoas da comunidade, motivando processos de auto-organização para além dos núcleos setoriais. Essa ação partiu de uma abordagem interdisciplinar entre as disciplinas de química e biologia, com os estudantes do Ensino Médio, a partir da identificação de graves problemas de falta de cuidado com as nascentes de água do acampamento. Adquiriu um valor social na medida em que partiu de uma necessidade que não nasceu na escola, mas da materialidade da comunidade e foi apropriada pela escola como um potencial formativo que extrapolou o interior da própria escola, possibilitando a articulação entre o estudo, que envolveu conteúdos escolares das disciplinas de química e biologia e uma forma de trabalho socialmente necessário, por meio do vínculo entre o trabalho intelectual e manual, pois após o estudo dos conteúdos, os estudantes, com o envolvimento de pessoas da comunidade realizaram a construção das proteções de fonte, com barreira e canalização da água, além 
da reconstituição da mata ciliar. No entanto, apesar da experiência possibilitar o vínculo entre uma forma de trabalho socialmente necessário e ensino, ficou restrita a um pequeno grupo de educadores, estudantes e pessoas da comunidade, também não potencializou suficientemente práticas de planejamento coletivo e auto-organização dos estudantes. (LEITE; SAPELLI, 2017).

A horta mandala foi construída com a participação de estudantes, educadores de horticultura realizada no acampamento. O grupo que constituiu o coletivo do projeto e foi responsável por elaborar e implementar a proposta, identificou que não tinha domínio teórico e prático dos processos e do objeto que queriam construir, que careciam, portanto, de estudos mais aprofundados sobre o que era e como construir uma horta mandala e sobre a agroecologia. (SAPELLI, 2017).

As experiências de agroecologia desenvolvidas pela escola Escola Itinerante Herdeiros da Luta de Porecatu, no município de Porecatu, Paraná, no âmbito do projeto foram a construção de uma horta mandala, que posteriormente foi ampliada para um sistema agroflorestal e a proteção de fontes d’água.

Segundo uma pessoa que era integrante da coordenação da escola ${ }^{3}$ no período em que foi realizado o projeto, já acontecia trabalhos com ou sobre a agroecologia na escola desde antes do projeto, nas discussões em sala de aula, em algumas práticas e nas tentativas de horta da escola. Segundo ela, o tema da agroecologia permeava a área das Ciências da Natureza e a última atividade de maior proporção antes da chegada do projeto foi no ano anterior (2014) com os estudantes do Ensino Médio, que estavam desenvolvendo um projeto de proteção de uma nascente, que teve continuidade com a vinda do projeto.

${ }^{3}$ Questionário aplicado em 14/05/2018.
A horta mandala foi construída ao lado da escola, com pouco envolvimento dos estudantes e professores. Realizaram práticas de adubação verde e adubação com matéria orgânica, além de pousio, para tentar reestruturar o solo. Inicialmente a horta foi utilizada para o cultivo de plantas medicinais e condimentares, porém definiram por ampliar o espaço para a produção de alimentos, depois que conseguiram construir o filtro para garantir a irrigação. Iniciaram a construção de um sistema agroflorestal, com uma produção diversificada também de hortaliças, plantas ornamentais e frutíferas, para criar também uma barreira nos arredores, devido à utilização de agrotóxicos na produção, perto do local da escola. (SAPELLI, 2017).

Para a realização da proteção de fontes a escola enfrentou resistência da comunidade, que ficou com receio de perder o uso da nascente se ela fosse protegida. Porém, aos poucos o grupo envolvido no projeto fez com que a comunidade compreendesse os benefícios na qualidade da água para as famílias. Foram realizadas as seguintes atividades: a limpeza e a construção de cerca para isolamento da área e para impedir a circulação de animais; o plantio de mudas de árvores nativas para reestruturação da mata ciliar e também a drenagem em duas fontes. (SAPELLI, 2017).

As experiências motivadas pelo projeto ficaram restritas a um pequeno grupo de estudantes, educadores e pessoas da comunidade, em termos de participação real no processo. Porém, a dificuldade na relação com a comunidade fez a escola se movimentar no sentido de ampliar o diálogo e fazer um processo de convencimento das famílias, em relação à importância do trabalho com a agroecologia.

A prática de agroecologia desenvolvida pela Escola Itinerante Valmir Motta de Oliveira, município de Jacarezinho, Paraná foi a construção de uma horta floresta. A 
escola compôs um grupo de pesquisa e experimentação em agroecologia, que iniciou as atividades com processos de estudo. A área escolhida foi a antiga horta escolar, em função da necessidade de reestruturação do solo que era muito arenoso e desgastado devido à intensa exploração pelo cultivo de cana-de-açúcar que era realizado na fazenda. Como o solo estava muito degradado, o grupo identificou que era necessário produzir biomassa para proporcionar uma estabilidade mínima ao sistema, otimizar a produção de matéria orgânica e manutenção da umidade para reestruturar o solo e recompor a diversidade biológica que foi perdida. Os passos utilizados para organizar a horta floresta foram: coleta de esterco de curral e folhas da mata para a produção de compostagem, produção de mudas de hortaliça, coleta e plantio de mudas de bananeira, preparo das linhas e canteiros de plantio, preparo de substrato, plantio de adubação verde, aplicação da compostagem, produção de mudas de plantas nativas por meio da técnica da alporquia, plantio de mudas produzidas e coletadas na comunidade, roçadas e podas. (SAPELLI, 2017).

No decorrer do projeto houve alguns limites, como o ataque de formigas na horta, o que motivou a realização de pesquisa envolvendo todas as turmas, junto às famílias do acampamento sobre possíveis práticas de controle. Também houve a limitação de tempo e disponibilidade de permanência para o desenvolvimento das atividades no local da horta, devido às pessoas envolvidas ir morar em locais distantes, o que dificultou o manejo, principalmente no período das férias escolares. Outro limite foi a pouca participação dos professores e da própria comunidade nas atividades, sobrecarregando o grupo responsável pelo projeto. (SAPELLI, 2017).

Apesar de todos os limites indicados em relação à experiência desenvolvida, identificamos como um grande potencial o papel que a escola exerceu nesta comunidade, no sentido de possibilitar às famílias o contato com a agroecologia, num local em que praticamente não existiam iniciativas neste sentido. Isso já é um passo considerável, em relação à função social da escola, pois pela mediação da mesma, as práticas desenvolvidas com o projeto se tornaram motivadores para algumas famílias aderir a formas de manejo de base agroecológica.

A experiência de agroecologia desenvolvida no âmbito do projeto pelo Colégio Estadual do Campo $1^{\circ}$ de Setembro, Assentamento Egídio Brunetto, em Rio Branco do Ivaí, Paraná, foi a construção de uma horta mandala. A escola optou por este modelo de horta porque o mesmo economiza água, aproveita melhor o espaço e permite o trabalho com uma diversidade de plantas, prevendo inclusive a inclusão de animais e a construção de um reservatório de água, porém optaram por incluir ao centro da horta um viveiro de mudas, com o objetivo de produzir mudas para o plantio na horta e para doar para a comunidade. Inicialmente constituíram na escola um coletivo de monitores responsável pelo projeto, envolvendo sete estudantes e três educadores. (SAPELLI, 2017).

Houve a realização de momentos semanais de estudo e de produção na horta, planejados coletivamente e divididos entre leituras e práticas. Indicam que sentiram a necessidade de estudos mais aprofundados para fundamentar as práticas agroecológicas que pretendiam desenvolver e destacam alguns dos temas que estudaram: a importância do Sol, água e nutrientes na produção de alimentos; indicadores biológicos; produção de adubos orgânicos; controle biológico; biofertilizantes e caldas; compostagem; germinação das sementes; técnica de alporquia para produzir mudas. Realizaram mutirões para garantir o manejo da horta, com práticas de recuperação de solo por meio de adubação 
verde, utilização de esterco, consórcios de plantas, controle de insetos com a utilização de caldas, dentre outras. (SAPELLI, 2017).

A experiência desenvolvida no âmbito do projeto, pelo Colégio Estadual do Campo Aprendendo com a Terra e com a Vida, Assentamento Valmir Motta de Oliveira, Cascavel, Paraná foi a construção de uma agrofloresta, para ser o espaço de exercício de práticas agroecológicas, numa área coletiva nas proximidades da escola. O trabalho foi realizado por estudantes, professores da Escola Municipal do Campo Zumbi dos Palmares e Colégio Estadual do Campo Aprendendo Com a Terra e Com a Vida e pessoas da comunidade. (SAPELLI, 2017).

A opção pela agrofloresta foi justificada pelo potencial para a produção de alimentos saudáveis para complementar a merenda escolar com hortaliças, tubérculos e frutos, pois os alimentos vindos do governo do estado e do município eram em sua maioria, produtos industrializados, enlatados e contaminados com agrotóxicos. Além de contribuir com a preservação do solo, aumento na diversidade de plantas e manutenção da biodiversidade existente. (SAPELLI, 2017).

As experiências desenvolvidas no âmbito do projeto, pela Escola Itinerante Herdeiros do Saber, Acampamento Herdeiros da Terra de $1^{\circ}$ de Maio, Rio Bonito do Iguaçu, Paraná foram a construção de duas agroflorestas, de uma horta coletiva e três proteções de nascentes. A definição por essas práticas se deu devido à importância de formar referências para o futuro assentamento, considerando que na região, nos próprios assentamentos vizinhos, uma questão muito preocupante é a contaminação das águas com agrotóxicos, em decorrência do modelo de produção hegemônico entre as famílias assentadas ser o do agronegócio. E em relação ao caso específico do acampamento, devido à intensa exploração madeireira, acabou devastando e destruindo muitas nascentes.

De acordo com informações obtidas com uma integrante da direção do acampamento ${ }^{4}$ e com uma pessoa da coordenação da escola ${ }^{5}$, que acompanhou o desenvolvimento do projeto e que é integrante de um dos grupos de agroecologia no local, o acampamento já desenvolvia desde a ocupação, algumas iniciativas de proteção de fonte, ou seja, para ela, as ações do projeto se colocam como continuidade de um processo que já ocorria. Relataram que para a construção da horta, a comunidade foi convocada por diversos momentos para realizar trabalhos nela, desde a construção até a plantação e manejo.

A partir destas experiências desenvolvidas por escolas vinculadas ao MST no Paraná, no âmbito do Projeto Formação em Agroecologia dos Jovens do Ensino Médio das Escolas Itinerantes do Paraná: do saber popular ao conhecimento científico para o cuidado com a terra e com a vida, podemos estabelecer algumas considerações sobre a materialização da relação educação e agroecologia e sobre a função social da escola na construção da agroecologia.

\section{Considerações sobre a função social das escolas vinculadas ao MST na construção da agroecologia}

Uma primeira questão a se considerar sobre a função social da escola é a necessidade de problematizar a forma escolar capitalista. O MST compreende a necessidade da educação escolar como elemento fundamental, considerando que o direito à educação foi historicamente negado aos camponeses, portanto, o primeiro sentido da luta por escola e

\footnotetext{
${ }^{4}$ Entrevista concedida à autora em 15/05/2018.

${ }^{5}$ Questionário aplicado em 18/05/2018.
} 
pela Educação no e do Campo projetada pelo MST é a afirmação de um direito fundamental do ser humano, necessário ao seu processo de humanização.

No entanto, compreender a relação entre escola e o MST na atualidade, implica em compreender a escola a partir da contradição - o novo que nasce do velho, o velho que convive com o novo. Nesse sentido, o MST luta pela construção de uma nova escola, de novas relações sociais, a partir das contradições da forma escolar capitalista.

A forma de escola que conhecemos hoje é fruto de uma construção social intrínseca ao desenvolvimento histórico da sociedade capitalista. Evidencia-se como uma instituição social disciplinadora, submetida aos interesses da classe dominante, que detém o controle dos meios de produção e que forja seu poder de dominação com base na exploração da classe trabalhadora. Entretanto, não é a escola em si que produz as classes sociais, ela reproduz a forma da sociedade capitalista em seu interior, a divisão social do trabalho, as relações de poder, incorporando tais elementos, oriundos de uma sociedade de desiguais que molda a forma da escola. Segundo Freitas (2010, p. 156),

Há razões para que se tenha aceito colocar a classe trabalhadora na escola. Ocorre que ela ensina, mesmo quando aparenta não ensinar. O espaço escolar está cheio de vivência. De fato, "a escola é uma relação" (Shulgin, 1924). Aprendem-se relações de subordinação no processo de gestão escolar; aprendem-se relações de submissão na sala de aula; aprendem-se valores e atitudes nas variadas vivências oportunizadas pela escola - sem que se tenha que aprender Português e Matemática. A escola produz a aceitação da vida e a submissão do aluno às regras vigentes e, em relação à classe trabalhadora, continua a sonegar conhecimento, distribuindo-o, quando o faz, segundo o nível que é esperado pelas condições gerais de funcionamento do processo de acumulação de riqueza.

O processo de inserção da classe trabalhadora na escola, local que antes se destinava apenas à formação da elite, mas que passou a ser destinado também à formação da classe trabalhadora, foi fruto da demanda de formação de força de trabalho para atender as necessidades do processo de desenvolvimento capitalista. No entanto, obviamente, a educação destinada às camadas dominantes sempre foi diferenciada da educação dos trabalhadores, limitada à oferta de elementos instrucionais e a um processo de subordinação dos estudantes, mas que não deixou de ensinar de alguma forma, em termos de apropriação do conhecimento científico, mesmo que de forma parcelada e fragmentada, distante da realidade e da vida.

Nesse sentido, a educação escolar que foi pensada para atender as demandas e interesses do capitalismo deu origem às tendências pedagógicas liberais, conservadoras, fundadas na divisão entre pensamento e ação. Assim, a forma escolar capitalista é constituída de elementos que a evidenciam como instituição disciplinadora para a vida social e produtiva e cumpre assim sua função de sustentar e reafirmar os valores do regime social dominante.

Compreendemos aqui, que a escola é uma relação, muitas vezes, de dominação, de subordinação. O foco central da escola é a sala de aula, mas todos os espaços da escola contêm concepções embutidas, lógicas de poder. A forma escolar se ancora numa lógica de relações de dominação e subordinação, que foi construída durante séculos, e que não é natural, existe justamente para consolidar os interesses da classe dominante. De acordo com Freitas (2010, p. 155), “[...] ao longo de séculos de capitalismo, a escola aprisionou o conteúdo estudado pelas 
ciências e autodeclarou-se a única credenciada para transmiti-los à juventude dentro de salas de aula."

Mas esta forma de escola hegemônica, historicamente construída, separada da vida da classe trabalhadora, que reflete os interesses da classe dominante, em sua forma e organização, não está isenta de contradições, e justamente por ser um espaço que foi ocupado pelos trabalhadores, involuntariamente e voluntariamente, tornou-se um espaço de contradição, de disputa de projetos societários e de educação.

O MST compreende que a educação escolar é um direito fundamental do ser humano, que historicamente foi negado aos trabalhadores, do ponto de vista de uma educação que humanize, que desenvolva as suas várias dimensões, na perspectiva de um educação omnilateral, para além de aliená-los e formá-los, enquanto força de trabalho para servir ao capitalismo. A educação escolar para o Movimento coloca-se, antes de tudo, como luta pelo direito à educação, porém vai mais além, pois ousou pensar seu próprio jeito de fazer a escola, como uma afirmação da necessidade do acesso ao conhecimento para a luta pela transformação social, por isso, concebeu uma proposta de educação e de escola que, inclusive, tem amparo na Constituição Federal, que no seu Artigo 206, indica que:

O ensino será ministrado com base nos seguintes princípios: I - igualdade de condições para o acesso e permanência na escola; II - liberdade de aprender, ensinar, pesquisar e divulgar o pensamento, a arte e o saber; III - pluralismo de ideias e de concepções pedagógicas [...]; IV - gratuidade do ensino público em estabelecimentos oficiais; [...] VI - gestão democrática do ensino público, na forma da lei. (BRASIL, 1988, n.p.).
Na medida em que o MST afirma a importância de lutar por um direito universal, portanto, também dos camponeses, e mais além, ousa a pensar seu próprio jeito de fazer a escola, como uma afirmação da necessidade do acesso ao conhecimento, a escola transforma-se num local de tensionamento, de disputa de projetos de educação, de agricultura e de sociedade, portanto, de luta de classes. Por isso, não basta alterar o conteúdo, é preciso mudar também a forma escolar.

O MST não nega o conhecimento, pelo contrário, afirma a necessidade do acesso ao conhecimento e à educação. $\mathrm{O}$ que o Movimento luta para superar é a forma escolar capitalista e essa luta apontou caminhos possíveis para a transformação da escola e resultou na formulação de uma concepção de educação e de escola, bem como a construção de uma proposta curricular que tem a formação humana como preocupação central.

Mas devemos considerar que a escola é uma construção e uma relação histórica imersa na sociedade de classes. A educação escolar não se faz separada dos interesses sociais presentes num determinado momento histórico, se faz também condicionada, enquanto instituição do Estado, portanto do capital, e se constituiu historicamente a partir de relações de poder e interesses de classes sociais antagônicas. Ou seja, a educação não é neutra e, contraditoriamente, ou está a serviço de uma determinada classe social ou de outra. A educação escolar que é pensada para atender as demandas e interesses do capitalismo deu origem às tendências pedagógicas liberais, conservadoras, fundadas na divisão entre pensamento e ação, entre trabalho intelectual e trabalho manual. (VIEIRA, 2016).

Apesar de reconhecer o caráter de classe do Estado e também da forma escolar historicamente construída, o MST entende que o financiamento para a implementação 
de sua proposta pedagógica é responsabilidade do Estado, portanto, de garantir as condições estruturais, respeitando a liberdade do Movimento para definir a forma e o conteúdo dessa proposta. Entretanto, mesmo com esse posicionamento do MST, essa condição não é assegurada, pois o Estado além de interferir no conteúdo e na forma das escolas, garante apenas uma política de financiamento mínimo, justificando que é decorrente do fato de as escolas de acampamento estarem localizadas em áreas de conflito e ocupação. Entendemos que essa justificativa do Estado não é válida, pois se observarmos as escolas de assentamentos, estas também não tem as condições adequadas asseguradas.

Apesar dos esforços para superar a forma escolar capitalista, as escolas vinculadas ao Movimento são submetidas a uma hierarquia administrativa do Estado que impede grandes mudanças. Mesmo com iniciativas importantes rumo à transformação sendo desenvolvidas, a exemplo das experiências de trabalho com a agroecologia, grande parte do trabalho desenvolvido na e pela escola é absorvido pela burocracia educacional do Estado, impedindo ou dificultando a continuidade e avanços dos processos.

$\mathrm{O}$ acesso ao conhecimento historicamente produzido pela sociedade é uma condição essencial para a formação nas novas gerações de camponeses e é uma tarefa específica da escola. A partir desse entendimento, o MST vem tentando criar e desenvolver mecanismos, desde suas práticas pedagógicas e ambientes educativos, para potencializar a formação dos estudantes nas diferentes dimensões que a vida exige e que, por certo, a sala de aula não dá conta de desenvolver. E no contexto da sociedade de classes, que expropria e aliena do trabalhador o resultado do seu trabalho, com uma forma escolar que produz sujeitos cúmplices ou executores alienados, que o MST afirma a união entre o trabalho e o ensino, como uma condição para a formação de lutadores e construtores, para a formação de seres humanos plenamente desenvolvidos. Nesse sentido, a formação omnilateral almejada pelo MST amplia as finalidades da educação, porque compreende que a formação das novas gerações não terá sentido se não for também para atender objetivos que são mais amplos, que perpassam, mas também ultrapassam a sala de aula e a própria escola.

A omnilateralidade é a finalidade última da educação e se realiza sobre o trabalho. Marx a entende como desenvolvimento total, completo, multilateral, em todos os sentidos das faculdades e das forças produtivas, das necessidades e da capacidade da sua satisfação. Exige um princípio unitário de comportamento humano, ou seja, uma coerência de atuação nas diferentes esferas da vida humana. (MST, 2012, p. 9).

O MST compreende que desenvolver processos de formação em agroecologia nas escolas, pela mediação do trabalho enquanto princípio educativo, na forma de trabalho socialmente necessário, é uma tarefa que não pode ser atribuída somente à escola, mas que a escola cumpre um papel fundamental, pois pode e deve potencializar tempos educativos que contribuam, mesmo que não na totalidade do potencial da agroecologia como base científica para a construção da Reforma Agrária Popular e para a formação da nova geração de camponeses.

Seria incoerência e contraditório de nossa parte, afirmar que o potencial educativo da agroecologia pode ser desenvolvido plenamente na escola. Nesse sentido, o papel da escola consiste em se desafiar a desenvolver a partir dela e preferencialmente no seu entorno, como parte de seu plano de estudo, formas de trabalho socialmente necessário que tenham como base a agroecologia. Para tanto, é preciso superar a ideia da escola como 
único local de educação. A formação humana também acontece fora da escola, por isso estas formas de trabalho precisam ter vínculo concreto com processos de produção, de construção e lutas que acontecem necessariamente fora da escola.

O objetivo da formação omnilateral e o correspondente trabalho pedagógico com as diferentes matrizes formadoras do ser humano estão no plano da estratégia. Por isso deve ser a perspectiva do nosso trabalho educativo no presente, nos limites impostos pelo quadro atual das contradições em que nos inserimos. As circunstâncias (trabalhadas) de cada local permitirão diferentes níveis de avanço, mas que implicam em ter clara a estratégia. (MST, 2012, p. 11).

Nesse sentido, compreendemos que o papel da educação e da escola como um dos locais onde acontece a formação humana é de importância fundamental. A socialização do conhecimento historicamente produzido pela humanidade é uma das tarefas da escola, mas a educação é maior do que a escola, é um processo de intencionalização da formação humana e o ser humano aprende e se desenvolve também e principalmente nas relações estabelecidas por meio do trabalho com o meio social no qual está inserido, não apenas no espaço escolar.

Uma segunda questão a se considerar, no que tange a relação conhecimento - ciência-saber, que se manifesta na agroecologia e na educação, é o que compreendermos por conhecimento. Na concepção materialista histórica dialética, o conhecimento é sempre uma construção cultural, portanto, social e histórica. Segundo Gehrke (2014), o conhecimento é marcado por um caráter sempre provisório e inacabado, condicionado pelo contexto sociocultural e pelas condições de sua produção e "[...] constitui-se enquanto processo mediatizado pelo diálogo e o método científico, pois se produz nas relações, perpassado pela ideologia que é indissociável do conhecimento.” (GEHRKE, 2014, p. 133).

O processo de construção do conhecimento, a partir da realidade, ganha sentido na medida em que reflete as representações sociais dos sujeitos, mas não implica necessariamente a produção de saberes originais, pois diz respeito também à apropriação, ressignificação e reconstrução de conhecimentos já existentes. A origem, a prática e a transformação dos diferentes tipos de conhecimento produzidos pela sociedade, responderam, ou não, às necessidades dos sujeitos que produzem/ constroem conhecimento, em suas práticas sociais e tempo histórico. (GEHRKE, 2014).

A ciência, segundo Lopes (1999), também é um objeto construído socialmente, cujos critérios de cientificidade são coletivos e específicos às diferentes ciências. Daí decorre a necessidade de questionar a possibilidade de definir de forma definitiva e universal o que é ciência. Corroboramos também da perspectiva da autora, de que diferentes saberes possuem legitimidade sem que necessariamente tenham que ser científicos, pois toda ciência é um saber, mas nem todo saber é científico.

Do exposto até aqui, podemos dizer que a escola, que carrega a especificidade de trabalho com o conhecimento, é espaço de reprodução, mas também é território de resistência e no campo das contradições abre-se a possibilidade de trabalhar para garantir a socialização do conhecimento científico, mas também o diálogo com os saberes populares. Nesse campo dialético em que a escola reproduz e ao mesmo tempo resiste, repousa um paradoxo, a natureza contraditória do conhecimento escolar.

Nesse sentido, é fundamental compreender o que Lopes (1999) define como as relações contraditórias entre três instâncias de conhecimento: científico, cotidiano e escolar. 
A autora considera que o conhecimento escolar compõe uma instância própria de conhecimento, que carrega a contradição de ter como objetivo a socialização do conhecimento científico e a constituição do conhecimento/saber cotidiano. Porém, há que se considerar que na sociedade de classes, o conhecimento escolar priva as classes exploradas do seu próprio saber, em decorrência da valorização exacerbada e ideológica do conhecimento científico como única forma de conhecimento válida, sendo que muitas vezes a escola não dá conta nem de garantir efetivamente o ensino dessa forma de conhecimento.

Afirmar que o conhecimento escolar é uma instância própria de conhecimento, não significa, no entanto, que a escola necessariamente produz ciência. De acordo com Gehrke (2014), na relação com a ciência e o cotidiano, é necessário reconhecer que a escola produz e reproduz conhecimento e que o conhecimento científico sofre um processo de transformação didática na escola para ser ensinado.

Outra questão, que é importante esclarecer, é que saber popular não é a mesma coisa que senso comum, embora ambos sejam formas diversas de conhecimento cotidiano. Os saberes populares são saberes produzidos a partir de práticas sociais de grupos específicos, porém não são conhecimentos cotidianos do ponto de vista da sociedade como um todo, como é o caso do senso comum. Assim, os saberes populares apontam para a especificidade e para a diversidade enquanto o senso comum para a universalidade e a uniformidade. Embora o senso comum tenha uma perspectiva de homogeneização, não é possível ainda afirmar a existência de um senso comum único. No processo de produção da ciência é necessário romper com o conhecimento aparente do senso comum, pois na sociedade capitalista a realidade é fetichizada, e quanto mais se permanece no campo das aparências, mais teremos um conhecimento que detêm no aparente, no evidente e no imediato. Ou seja, para produzir ciência é necessário romper com o conhecimento aparente do senso comum e elaborar sua crítica, mas isso não quer dizer que a ciência tenha que ser considerada como única forma de conhecimento válida. Por sua vez, valorizar os saberes populares não necessariamente tem que se estabelecer uma igualdade epistemológica entre as diferentes formas de saber e devemos ter cuidado para não atribuir a cientificidade que não possuem. As diferentes formas de saber são possíveis e válidas dentro dos limites que apresentam, independente de serem científicos ou não. Mas uma coisa é essencial, todas as formas de saber devem ter como objetivo a superação do senso comum. (LOPES, 1999).

E o que a escola tem a ver com isso? Justamente por carregar a especificidade do trabalho com o conhecimento, e ter como função social a socialização do conhecimento científico, sem perder de vista que não existe neutralidade na ciência e na educação, podemos dizer que trabalhar com o conhecimento científico implica, necessariamente, desmistificar uma realidade que se apresenta na forma aparente como pronta e acabada.

Nesse sentido, no âmbito educacional, das ciências e mesmo na agricultura, considerando a forma escolar capitalista e o modelo do agronegócio como formas hegemônicas de "produzir" conhecimento, há uma tendência reducionista de racionalidade ocidental, de tentar reduzir diferentes saberes a uma única razão. Isso seria uma impossibilidade, considerando que os diferentes saberes são resultado da diversidade cultural da sociedade de classes e que estes não podem se igualar do ponto de vista epistemológico. Há uma tradição seletiva dos saberes, que é fruto das lutas e conflitos de classes sociais, que atua no sentido de deslegitimar alguns saberes e de valorizar dados conhecimentos em detrimento de outros. Essa tradição foi fortemente 
incorporada pela escola, pois muitos conhecimentos são excluídos e outros são privilegiados na organização do currículo escolar, que de uma forma geral, resulta de um processo de estratificação e compartimentação do conhecimento e que produz e reproduz uma hierarquização social dos saberes, em que prevalece uma perspectiva positivista e cartesiana de conhecimento nas ciências, expressa na constituição do conhecimento escolar. (LOPES, 1999).

A forma escolar reforça uma razão instrumental que atua de maneira coercitiva sobre os saberes não científicos para deslegitimá-los, contribuindo assim para a reprodução das relações sociais capitalistas. O processo de diferenciação e compartimentação do conhecimento é uma condição necessária para que a classe dominante tenha seu conhecimento legitimado como superior. É uma expressão da divisão social do trabalho e não será superado sem que sejam transformadas as relações sociais de produção. (LOPES, 1999).

Nessa perspectiva, essa razão instrumental do conhecimento fragmentado, decorrente da divisão social do trabalho, fortalece a separação entre concepção e ação, tanto na escola, quanto na agricultura, pois na lógica do agronegócio, coloca os agricultores apenas como "consumidores" de conhecimentos e técnicas vindas de fora.

É importante destacar que a agroecologia não descarta a necessidade da ciência e da tecnologia, mas propõe um diálogo de saberes entre os conhecimentos científicos e os conhecimentos dos camponeses ${ }^{6}$, que considere e integre as diferentes dimensões e determinantes que a compõem. Nesse sentido, os agricultores não são apenas consumidores de conhecimento, pelo contrário, se reconhece o papel do camponês como sujeito

${ }^{6}$ Considerando também que o conhecimento técnico pode ser tanto científico, quanto empírico. que tem uma posição ativa e papel essencial no processo de construção do conhecimento na agricultura.

A agroecologia envolve um diálogo de saberes entre os conhecimentos dos camponeses e um conjunto de conhecimentos científicos que permite entender a diferença entre produzir alimentos com a natureza, e não contra ela, num processo de coevolução natural e social, que considera o ser humano como parte da natureza. Assim, oferece as bases científicas para a construção da agricultura camponesa com base agroecológica e para a formação das novas gerações de camponeses. A apropriação dessas bases científicas e conhecimentos agroecológicos é uma tarefa educativa que não diz respeito apenas à escola, porque é muito maior que ela, porém, a escola pode e deve ter uma contribuição específica, para materializar o vínculo orgânico entre esse projeto educativo com o programa de Reforma Agrária Popular, no bojo da luta contra a lógica do agronegócio ou o modo capitalista de fazer agricultura. Inserir a escola nessa grandiosa tarefa coloca as questões ambientais em outro patamar, para além da "educação ambiental" preconizada e hegemonizada pela ideologia liberal burguesa, pois integra o estudo da agroecologia à busca por desvendar as determinações do modo capitalista de fazer agricultura e suas formas de relação com a natureza, para a tomada de consciência da interconexão entre a destruição ecológica e as agressões contra as condições de existência dos trabalhadores camponeses. (MST, 2016).

A divisão social do trabalho na sociedade capitalista produziu a divisão social do conhecimento e no processo de produção do conhecimento, a separação entre concepção e execução, entre trabalho intelectual e trabalho manual. Em relação ao processo de produção do conhecimento e à agricultura, a sociedade de classes dissociou aquilo que em nossa vida 
cotidiana é inseparável, o pensar do fazer, o ser humano da natureza. A necessidade de superar essa dicotomia coloca novamente em conexão a agroecologia e a educação.

Nesse sentido, na agroecologia, a relação teoria e prática é fundamental, permitindo ao camponês pensar sobre o que fazer, como fazer e por que fazer. Traz a exigência de planejar o processo produtivo como um todo, o que no modo de produção capitalista se apresenta como uma impossibilidade, por fazer dos camponeses simples executores e consumidores.

A agroecologia, enquanto matriz produtiva que possibilita a construção de novas relações socioprodutivas, permite a aproximação entre o trabalho intelectual e o trabalho manual, entre a teoria e prática. Nessa perspectiva, o pilar fundamental da matriz formativa que orienta a construção da relação educação e agroecologia no MST é o vínculo necessário entre escola, trabalho $e$ produção. A agroecologia passa a integrar o plano de estudos das escolas na perspectiva de apropriação de conhecimentos sobre e desde o trabalho na agricultura e de inserção dos estudantes em formas de trabalho socialmente necessário, em processos de produção agrícola de base agroecológica. (MST, 2018b).

Na escola, a agroecologia pode contribuir na articulação entre teoria e prática como unidade dialética voltada à formação do ser humano, pois os sujeitos que a constroem precisam se apropriar do conhecimento teórico e prático sobre ela. A construção da Agroecologia enquanto teoria articulada indissociavelmente à prática abre possibilidades para os estudantes e camponeses se apropriarem do processo de produção na medida em que vai tomando consciência da necessidade de construir outra relação com a natureza e com os demais seres humanos. (JOHANN, 2015).
Nesse sentido, a agroecologia está em plena sintonia com a luta pela transformação da forma escolar capitalista e com os objetivos formativos que apontam para a formação de lutadores e construtores, de novas relações sociais e produtivas.

Por todos os elementos apresentados, compreendemos que é possível afirmar que a forma escolar capitalista e o processo de fragmentação do conhecimento escolar que decorre dela, não ajuda a entender a agroecologia na amplitude e complexidade de dimensões, conexões e relações que a envolvem. Essa forma de escola não comporta o trabalho com a agroecologia, numa perspectiva de totalidade.

Compreendemos que na natureza e na realidade, nada é isolado, tudo se relaciona, por isso o método científico da totalidade nos faz compreender as relações e conexões da realidade como um todo estruturado, síntese de múltiplas determinações. Por isso, trabalhar a agroecologia, na perspectiva da totalidade, implica assumir esta categoria como um princípio epistemológico e uma exigência metodológica, para compreender a singularidade da agroecologia, suas múltiplas determinações, suas mediações com o particular e o universal, na totalidade concreta. Nesse sentido, a agroecologia é uma singularidade entendida como um momento de um determinado todo, que ganha concretude, como expressão do universal, pois não pode ser compreendida descolada da materialidade que a produziu. Representa, portanto, um espaço/momento de articulação na luta de classes, para a mudança da totalidade, que é nesse caso, a ordem social capitalista e suas relações sociais e de produção.

\section{Considerações finais}

A realização do projeto "Formação em Agroecologia dos Jovens do Ensino Médio das Escolas Itinerantes do Paraná: do saber 
popular ao conhecimento científico para o cuidado com a terra e com a vida", por meio da parceria estabelecida entre o MST com uma universidade (Unicentro), motivou o desenvolvimento de debates e de práticas agroecológicas que afloraram algumas contradições presentes na forma de produção das comunidades envolvidas.

A materialidade destas evidencia que a produção da existência das famílias camponesas está sob a hegemonia do modelo do agronegócio, mesmo nos acampamentos. Nessas comunidades, principalmente nos acampamentos, dado o vínculo mais efetivo com processo de luta e enfrentamento do MST, há um debate político marcado pela disputa de projetos de agricultura (agronegócio X agricultura camponesa de base agroecológica).

Nesse sentido, desenvolver ações que fortaleçam o debate da Agroecologia nas escolas, bem como sua relação com o conhecimento científico é uma tarefa fundamental, tendo em vista que se trata do projeto de educação, de campo e de sociedade que o MST busca construir e estão essencialmente vinculados a construção da Reforma Agrária Popular. Assim, a Escola do Campo, como espaço de referência das comunidades camponesas, e no caso das escolas de acampamento e assentamento, que carregam a especificidade do vínculo com processos de luta do MST, tem a função de contribuir na formação da nova geração de camponeses e construir conhecimentos capazes de compreender as contradições presentes no campo e na sociedade, de forma geral e de responder às demandas de formação agroecológica de estudantes, professores e agricultores.

Considerando os limites da forma escolar, além da materialidade das comunidades envolvidas, a realização do projeto e as ações que este possibilitou, compreendemos a agroecologia, nesse caso, foi trabalhada pontualmente, dependendo das condições objetivas e circunstanciais de cada escola ou comunidade, com ações específicas e pontuais (construção de hortas, agroflorestas, proteção de fontes, na escola ou no entorno). A maioria das escolas não conseguiu dar continuidade às ações de trabalho com a agroecologia que foram desencadeadas por meio do projeto.

Essa dificuldade das escolas em continuar os processos iniciados por conta própria, demonstra a importância de recursos públicos (como os que financiaram o desenvolvimento do projeto) e da construção de políticas públicas que subsidiem o avanço da agroecologia, considerando as condições materiais das escolas, que já possuem condições precárias e das próprias comunidades dos acampamentos e assentamentos. $\mathrm{O}$ apoio financeiro se demonstra uma condição para construção de experiências para a implantação da agroecologia. Por outro lado, demonstra que muitas vezes os sujeitos das comunidades e as próprias escolas ficam condicionados ao apoio financeiro externo de projetos e à obrigatoriedade das ações que estes estabelecem como metas. É necessário que as comunidades e escolas também assumam a responsabilidade da tarefa de desenvolver processos de formação e experiências de trabalho com a agroecologia, sem ficar refém de agentes ou projetos externos.

A agroecologia é muito maior que uma horta, uma agrofloresta ou uma proteção de fonte, é uma construção social que envolve processos e relações sociais, ambientais, políticas, que exige a apropriação de um conjunto de conhecimentos. Porém, mesmo que estas práticas realizadas pelas escolas sejam pequenas iniciativas com várias limitações, possibilitaram colocar o trabalho com a agroecologia num novo patamar, ainda não o ideal, mas o possível no momento. Vale ressaltar também que inserir a agroecologia nas escolas, quando ela não existe ou ainda está limitada a pequenas iniciativas isoladas em acampamentos e 
assentamentos, não é uma tarefa fácil. E por meio das ações do projeto nas escolas, essa inserção se deu em diferentes níveis, tanto na escola, quanto na relação com a comunidade, de introduzir, aprofundar, consolidar, vivenciar experiências com a agroecologia.

Um elemento importante que identificamos a partir da participação nos processos de formação, foi que as escolas já apresentavam uma base de conhecimento e debates sobre a agroecologia, além de algumas ações já desenvolvidas, como, por exemplo, as atividades da Jornada Cultural da Alimentação Saudável, o que demonstra já um avanço do MST, em termos de orientação acerca da importância das escolas trabalharem questões como agroecologia, produção e consumo de alimentos saudáveis.

Mas reconhecemos os limites e contradições dos processos desenvolvidos. As escolas não exploraram de forma aprofundada o potencial educativo da agroecologia, as atividades ainda permaneceram como um trabalho desconectado ou que estabeleceu poucas relações com a dimensão do ensino, portanto do conhecimento científico, do trabalho dos professores. Envolveram poucas pessoas considerando a dimensão das escolas e comunidades envolvidas. As escolas não conseguiram, de forma geral, continuar o processo, após o término do projeto, salvo exceções de locais nos quais a comunidade se envolveu de alguma forma e garantiu algumas ações.

Compreendemos que é de extrema importância desenvolver ações que ajudem no processo de inserção da agroecologia no ambiente escolar. Esta relação, além de necessária para a luta do MST e a construção da Reforma Agrária Popular, também demonstra um potencial educativo que pode ajudar a qualificar o trabalho pedagógico e processo de ensino/aprendizagem nas escolas, bem como proporcionar uma formação mais crítica, para analisar e intervir na realidade, considerando o embate entre lógicas distintas de produção na agricultura.

Destacamos também, a importância de uma abordagem metodológica que ultrapasse os limites físicos da sala de aula e da escola, adentrando na comunidade e nas unidades de produção familiar dos estudantes, bem como o fortalecimento de outros espaços de formação e desenvolvimento, que possibilitem a participação e o exercício da auto-organização na vida social da comunidade e para além dela (movimentos sociais, associações, cooperativas), fortalecendo assim uma perspectiva de formação que ultrapasse os muros da escola e vincule-se à vida do entorno da escola.

A agroecologia pode e deve ser mais que um projeto dentro da escola. Esse desafio consiste em desenvolver processos que construam conhecimentos capazes de desvelar as contradições presentes no campo e as relações que ali se estabelecem. A função da escola poderia ser de, pelo menos, permitir que os estudantes e também os professores, compreendam a agricultura camponesa de base agroecológica como um processo de produção da existência, uma vez que é trabalho e que, além de produzir alimentos, constitui identidade de quem vive e trabalha no campo.

A partir do conjunto de experiências apresentadas, das proposições e considerações em relação à função social da escola, é possível afirmar que a escola não dá conta da grandiosidade da tarefa de construção da agroecologia, mas ela tem um grande potencial de possibilitar a sua inserção no contexto escolar, bem como abrir portas para a atuação do MST nessa construção.

Entendemos que é justamente o vínculo com a organização social e com processo de organização, de produção e de lutas para além da escola, que necessariamente garante 
a unidade na estratégia e a sintonia com a luta pela transformação social.

Nessa perspectiva, também reafirmarmos que não basta alterar o conteúdo e mesmo a forma escolar, o que também e fundamentalmente precisam ser enfrentadas e superadas são as relações sociais de produção do sistema capitalista, para romper com a lógica de dominação do capital na educação e na agricultura.

\section{Referências}

CALDART, R. S. Pedagogia do Movimento e Complexos de Estudo. In.: CALDART, R. S.; SAPELLI, M. L. S.; FREITAS, L. C. (Orgs.). Caminhos para a transformação da escola 3: organização do trabalho pedagógico nas escolas do campo, ensaios sobre os complexos de estudo. São Paulo: Expressão Popular, 2015.

. Pedagogia do Movimento Sem Terra. São Paulo: Expressão Popular, 2004. BRASIL. Constituição (1988). Constituição da República Federativa do Brasil. Brasília: 1988. Disponível em: <http://www. senado.leg.br/atividade/const/con1988/ con1988_12.07.2016/art_206_.asp>. Acesso em: 20 ago. 2018.

FREITAS, L. C. A escola única do trabalho: explorando os caminhos de sua construção. In.: CALDART, R. S. (Org.). Caminhos para transformação da escola: reflexões desde práticas da Licenciatura em Educação do Campo. São Paulo: Expressão Popular, 2010. p. 155-178.

GEHRKE, M. Contribuições da práxis para a constituição da Biblioteca Escolar do Trabalho a partir da Educação do Campo. 2014. 264 f. Tese (Doutorado em Educação). Universidade Federal do Paraná - UFPR, Curitiba, 2014.
JOHANN, P. D. A formação teóricoprática do técnico em agroecologia na escola 25 de Maio de Fraiburgo/SC. 2015. 76 f. Dissertação (Mestrado em Agroecossistemas) - Centro de Ciências Agrárias. Universidade Federal de Santa Catarina, Florianópolis, 2015.

LEITE, V. J.; SAPELLI, M. L. S. Possibilidades de trabalho pedagógico com a agroecologia no caminho para transformação da escola: reflexões desde práticas do MST/Paraná. In.: CALDART, R. S. (Org.). Trabalho, agroecologia e estudo nas escolas do campo. Coleção Caminhos Para Transformação da Escola Volume 4. São Paulo: Expressão Popular, 2017. p. 7889.

LOPES, A. R. C. Conhecimento escolar: ciência e cotidiano. Rio de Janeiro: UERJ, 1999.

MARX, K. O capital: crítica da economia política: livro I: o processo de produção do capital. São Paulo: Boitempo, 2013.

MST. Reforma agrária popular, agroecologia e educação básica. Sistematização feita por Roseli Salete Caldart em fevereiro de 2018a.

Guia de estudos RAP/ Agroecologia para a educação básica. Documento sistematizado por Roseli Salete Caldart, para a sessão de trabalho em Chapecó-SC, 24 e 25 de abril de 2018b.

Categorias pedagógicas que podem nos ajudar na tarefa proposta para a sessão de Trabalho Viamão-RS. 20 e 21 de junho de 2017a.

Memória geral da sessão de trabalho agroecologia $\mathrm{e}$ trabalho nas escolas de educação básica. Viamão-RS: Centro de Formação Sepé Tiaraju, 20 e 21 de junho de 2017b. 


\section{Relatório do seminário educação} em agroecologia nas escolas do campo. Veranópolis-RS: Instituto de Educação Josué de Castro, 16 a 18 de junho de 2016.

Plano de Estudos. Cascavel-PR:

Unioeste, 2013.

- Relatório síntese do seminário

"Educação Politécnica e Agricultura Camponesa”. IEJC - Instituto de Educação Josué de Castro. Veranópolis-RS: março de 2012.

Dossiê MST Escola: documentos e estudos 1990-2000. Caderno de Educação No13. Veranópolis-RS: ITERRA - Instituto Técnico de Capacitação e Pesquisa da Reforma Agrária, 2005.

SAPELLI, M. L. S. (Org.). Agroecologia: do saber popular ao conhecimento científico para o cuidado com a terra e com a vida. Caderno de Educação do Campo volume 2. Guarapuava: Apprehendere, 2017a.

- Escolas do MST: 15 anos de itinerância e resistência no Paraná. Relatório da Licença Sabática. 2017b.

VIEIRA, T. C. L. A forma escolar e a autoorganização dos estudantes: potencialidades e contradições para o MST. In.: SAPELLI, M. L. S.; GEHRKE, M.; MARIANO, A. S. (Orgs.). Vozes da Resistência II: sobre práticas educativas nos tempos e espaços ocupados pelo MST. Guarapuava: Unicentro, 2016. 